\title{
THE 2nd AFIR INTERNATIONAL COLLOQUIUM
}

The 2nd AFIR International Colloquium was held in Brighton, England from April 16-19, 1991. The Colloquium was presented in much the same manner as the first one in Paris a year earlier, with some exceptions. The British organisers permitted the authors of papers more time to formally present their findings and thus needed to use concurrent sessions for topics judged to be away from the mainstream interest. The business meetings were organised with two invited lectures, six plenary sessions, and four sessions at which a total of nineteen concurrent meetings took place.

The guest lectures were given by Brian Quinn, an Executive Director of the Bank of England, who has special responsibility for banking supervision, and whose name has been in the newspapers subsequently because of his responsibility for the affairs of the Bank of Credit and Commerce International. His talk on some of the problems of banking supervision was prophetic.

The other guest lecture was given by Professor Michael Brennan of UCLA, who gave an extensive review of the economic fundamentals that underlie much of the work of modern financial economists, and hence of actuaries aspiring to contribute to AFIR.

Since it was impossible to attend all the sessions at which papers were presented, I have chosen to review those that I personally found to be of greatest interest. By following this route, I am unable to do justice to many of the valuable contributions, but they can be found in the full set of papers published in the four volumes of Colloquium proceedings. At the beginning of the first volume is a 20-page introductory review by David Wilkie, Chairman of the Scientific Committee.

Each session followed the same format. A designated "opener" set the stage for the subject area, providing some necessary background, outlining significant issues and developments, and providing a brief overview of the various papers. Authors of the papers were then given an opportunity to highlight their work and offer comments and results not in their published material. After questions from the floor, a designated "closer" summarised and opined on the various contributions from the authors and others.

The first plenary session covered banking and credit and included papers on the French banking system where many actuaries are employed. Of particular interest to me was the paper "Credit Risk Research: Private Placement Bonds and Commercial Mortgage Loans" by Gery Barry, who heads a Society of Actuaries research group studying this topic. Their research group has struggled with the issue of how to define a credit risk event and how to measure credit risk loss for a private transaction that tends to be renegotiated when the borrower experiences financial difficulty. European institutional investors have 
generally avoided credit risk, but US institutional investors seem prone to take it on and then live or die by managing it successfully or mismanaging it. The recent difficulties and failures of many US life insurance companies underscore the importance of understanding this subject better. A related risk for these types of investments, not addressed by the Society of Actuaries research group but highly topical in the US, is "illiquidity risk" that threatens the solvency of a financial institution suffering from a public crisis of confidence and thus exposed to a severe cash flow drain.

The second and third plenary sessions covered the topic of interest rate and yield curve models. Two papers caught my attention. Robert Reitano delivered a very understandable lecture on the risk of non-parallel shifts in the yield curve. He introduced the concept of "partial durations" that measure an asset's or liability's market value sensitivity to a shift in a single segment of the yield curve. Summing all partial durations gives the familiar "total" duration measure. Boulier and Sikorav tested whether the yield curve for French government bonds obeys the Ho and Lee model of interest rate dynamics. Although the Ho and Lee model performs reasonably well, the authors emphasise the need to go beyond in two areas: in the real world, short-term yields are more volatile than long-term yields and yield curve dynamics depend on more than what happens to the short-term interest rate. Also, for the originally-published form of the Ho and Lee model, there is the problem of negative interest rates occurring with significant probability.

One of the interesting concurrent sessions featured papers on non-linear models and chaos theory. Chaos theory has captured the imagination of many actuaries and indeed might have intrigued Albert Einstein by offering an alternative theoretical foundation for quantum mechanical phenomena. Many philosophical questions arise when the relationships between stochastic systems and non-linear deterministic systems are considered. For example: what errors, if any, will occur when a system that is actually non-linear, deterministic, and chaotic is modelled as if it were purely stochastic? The standard tests for detecting the presence of non-linear deterministic behaviour assume a very long data series. Maddocks, Nisbet, Nisbet and Blythe used such a test, based on the concept of "correlation dimension", and found evidence of deterministic behaviour in weekly data for the Financial Times All Share Index (1965-1989), the Dow Jones Index (1969-1986), the Standard and Poor Composite Index (1965-1986), and the Nikkei Index (1966-1989). There remains a question, however, as to whether their data transformations introduced spurious correlations, and a question as to whether the observed behaviour is chaotic (with a strange attractor present), not merely deterministic. We await their further results.

In my opinion, the real highlight of the Colloquium was the presentation of two invited papers by Andrew Smith: one on option pricing formulas and another on the use of martingales in actuarial work. In his presentation at the Colloquium, Dr Smith treated the audience to simple examples illustrating a few of the points raised in his papers. His second paper demonstrated how easily a number of key results found in actuarial science can be derived from 
basic properties of martingales. That paper should be studied carefully by all actuaries aspiring to be of "the third kind," according to Professor Bühlmann's taxonomy. Professor Neave's carefully prepared and thoughtfully presented introduction to the session on theoretical developments also deserves special mention. It set the stage perfectly for Smith's martingale paper and for the related paper "Generalised Arrow Pricing to Understanding Financial Markets" by Ami, Kast and Lapied.

Brighton does not have the same attractions to the visitor as Paris, but nevertheless the organisers had arranged a wide programme of visits and entertainments for accompanying persons during the day and for participants too in the evenings. These included visits to the attractive towns and villages of Sussex, two castles steeped in English history, a vineyard (yes, there is English wine of quite respectable quality), theatrical performances, and even, for those who prefer gambling to insurance, greyhound racing, at which the bookies seemed to be confounded by a large number of punters, under instructions from Hans Bühlmann, who all chose to put their money on the same dog; I cannot say whether their performance in this field was better or worse than that of investment managers.

There will not be an AFIR Colloquium in 1992 because the 24th International Congress of Actuaries in Montreal is accorded the spotlight for the year. The 3rd AFIR Colloquium will be held in Rome in 1993, an event we eagerly await after the outstanding achievements turned in at Paris and Brighton.

JAMEs A. Tilley 